\title{
Best practice in communications training for public engagement with science, technology, engineering and mathematics
}

\author{
Joana Silva and Karen Bultitude
}

\begin{abstract}
Effective training in key communications skills is critical for successful public engagement. However, what are the secrets to designing and delivering an effectual training course? This paper outlines key findings from a research study into communication training programmes for public engagement with STEM (science, technology, engineering and mathematics). The research focused on training in direct communication methods, (as separate from media training) and encompassed both trainers and trainees, the latter group spanning across both scientists and explainers. The findings indicated that training courses are effective at increasing involvement in science communication events and trainees feel more confident and able to engage due to training. An interactive style was found to be a key element of training courses. Demonstrations of good practice followed by own performance with feedback were also important, preferably involving a 'real' audience. A list of guidelines on best practice has been developed which offers practical advice.
\end{abstract}

\section{Context}

The significant link between the communication of research to the public and economic progress has been recognised by the European Union. In 2005, the Communicating European Research (CER) conference was held to "promote more and better communication on science and research". ${ }^{1}$ Maeseele $^{2}$ interprets this in light of the Lisbon Strategy set out in 2000 in which EU Heads of State agreed to scale up R\&D investments to $3 \%$ of GDP by 2010 . The rationale is that more and better communication will lead to more R\&D (research and development) investments, with a consequent increase of jobs and growth. Ultimately, Maeseele concludes that more and better communication of science is regarded by the EU as crucial for the economic progress.

Specific EU member states, as well as other countries internationally, have also acknowledged the fundamental importance of science communication to their societies. For example within the UK it is increasingly recognised that communication of research results can have significant impact on members of the public, leading to changes in their views, attitudes and behaviour. ${ }^{3}$ The UK Department for Innovation, Universities and Skills (formerly known as the Office of Science and Technology, OST) believes ${ }^{4}$ that public perceptions of science play an increasingly important role in policy development. A 2005 survey $^{5}$ stated that science policy relies ever more on public involvement and engagement, communication of science and dialogue, as well as on science and its social and ethical implications.

Within this context, key actors in science - researchers and engineers, science institutions, and science centre and museum explainers - are increasingly being called upon to engage directly with the public. Various training programmes for public engagement with Science, Technology, Engineering and Mathematics (STEM) have been developed to provide both scientists and explainers with the support they need to be able to communicate effectively. However, to date each training programme has remained relatively isolated, pursuing its own path with little to no comparison between different programmes, and lacking an over-arching investigation of best practice.

Comparative evaluation of communications training programmes is constricted by the wide diversity of course formats and delivery mechanisms. Programmes can range from external one-day training courses to in-house workshops at science centres and museums to formal degree programmes which usually take a 
year or more to complete. Training can be aimed solely at scientific researchers, at specific museum staff such as explainers, or at science communicators in general, consisting of a bespoke course specifically designed for a set of trainees or an off-the-shelf model which individual delegates choose to attend.

An example of a one-day course is the Communication Skills Training offered by the Royal Society in the UK. This training "equips scientists with the skills to communicate their science on a non-technical level, clearly and confidently to a variety of audiences". ${ }^{6}$ It is a one-day workshop for scientific researchers that covers different topics relevant to effective communication, for example, how to get messages across clearly and presentation techniques. A slightly more extended version is the annual Science Communication Masterclass ${ }^{7}$ run by the University of the West of England in Bristol, UK. The Masterclass is a five-day intensive course created to provide professional development in science communication and attracts both scientists with a passion for science communication as well as professional science communicators.

Academic courses in science communication are now available in many parts of the world, ${ }^{8}$ offering optional modules as part of wider degrees (often linked into science-specific subjects) or dedicated programmes focusing specifically on science communication, at both undergraduate and postgraduate level.

In the specific case of science centres and museums, recent work ${ }^{9}$ has demonstrated a wide variation in support offered to internal 'explainer' staff, with the report authors stating that "many institutions do not organize a specific training course for the explainers, or organize only very short courses. An internal, long course is organized just in 12 museums out of 37, and external courses are mentioned in just 1 case".

The variation between these different sorts of training opportunities obviously has an effect on the depth of learning and engagement experienced by the participants. A one-day course cannot hope to achieve the same impact as an extended academic qualification which incorporates extensive time for reflection and feedback. Similarly, a course delivered by internal colleagues will be received differently to one which brings in externally-recognised experts - in both positive and negative respects, since the internal deliverers are likely to better understand the needs of the participants however due to over-familiarity their input may not be so readily accepted.

Since little research currently exists in this area, this paper does not at this early stage aim to distinguish between the effects of all these myriad factors. Instead, it aims to provide a broad brush comparison of different training experiences, identifying best practice in training methodologies. The intention is to thereby contribute to the improvement of communication skills and to the effectiveness of the public engagement field in general.

\section{Trainees - a profile}

Preliminary consideration of existing training provision within the field identified two key recognisable groups who have a prominent place in communicating STEM subjects directly to public audiences, and for whom appropriate skills training is currently available: STEM researchers and science centre or museum explainers. Whilst obviously there are other groups involved in science communication (e.g. journalists, institutional press officers, outreach staff etc.) either their work is more focused within the media domain or there is little provision for large scale training. For this reason the research focused on two distinct 'trainee' groups: researchers and explainers.

By actively undertaking scientific research and practice, researchers (scientists, engineers, mathematicians etc.) are in an obvious position to communicate to the public. They are the best informed on the details and implications of their own research and hold a privileged position in the public sphere. ${ }^{5}$ However, as recognised by the European Network of Science Education Teachers (ENSCOT), there are "increasing demands on scientists - to communicate, to be involved in public dialogue and debate, to make science part of an integrated culture - demands for which they are ill-prepared by their formal training". ${ }^{11}$ Scientists themselves also acknowledge a need for encouragement, guidance, and skills development in communicating their research. ${ }^{5}$

Explainers working within science centres and museums - the facilitators of the visitor's experience ${ }^{12}-$ are on the interface of science and society. Explainers in science centres and museums represent a very important group with key public-facing responsibilities. Within the UK a recent report on Public Attitudes to Science ${ }^{13}$ highlighted that a fifth of the population said they had visited a science museum or science centre in the 12 months prior to the survey and a quarter had visited a zoo. This data matches well with findings from the 2005 Special Eurobarometer survey, ${ }^{14}$ in which $16 \%$ of people acknowledged 
attending science museums, technology museums or science centres, and $27 \%$ had visited a zoo or aquarium. If explainers are given relevant training to improve their performance and skills, a substantial impact on society could be achieved. ${ }^{9}$

Training programmes have been developed to meet the needs of researchers and explainers. Several communication training programmes provide the support scientists need and help them develop the skills to communicate clearly and confidently to different audiences, as well as with the media. However, Bauer et al. note ${ }^{15}$ that worldwide "...in all but a few countries, little is done to prepare scientific researchers for communication activity with lay audiences, despite the commitment expressed in official documents". Similarly, science centres and museums provide training for their explainers, although the programmes differ significantly from one institution or country to another. ${ }^{12}$ Obviously, training needs vary in different situations and even for different individuals,${ }^{16}$ nevertheless further strategic direction regarding training for researchers and explainers is clearly required. At present, however, very little is publicly known about the impact of individual training on scientists or explainers. The extent of evaluation within existing programmes is variable, and even when evaluation does take place, trainers are frequently reluctant to make the findings public, often for (understandable) commercial reasons.

This research focused on communication training programmes for public engagement with STEM. Programmes of this type aim to develop the trainees' skills and confidence in direct communication with public audiences and promoting dialogue, rather than focusing solely on how to deal with the media. Direct engagement with public audiences is a relatively unique feature of STEM communication and one which is pertinent to both researchers and explainers. For this reason, programmes which focused solely on media skills were disregarded within this research, in favour of public-oriented training.

This research study endeavoured to identify positive trends in the area of communication training and to promote improvements in these trainings that ultimately will enhance public engagement with science. A broad brush evaluative approach was therefore taken, which focused on a variety of training programmes, and addressed all of the different actors involved in the training schemes. By incorporating the trainees' feedback and identified best practice, a foundation has been created from which programme providers can develop programmes that better suit those undertaking training.

\section{Methodology}

A combination of quantitative (online survey) and qualitative (semi-structured interviews) methods were used in this study.

\section{Online Survey}

The survey was designed using the online survey tool SurveyMonkey. ${ }^{17}$ The survey consisted of two sets of questions; one for trainers and one for trainees. Respondents were directed to the appropriate set of questions after selecting their role in question 1 of the survey.

The question set for trainers comprised a total of 16 questions, while the set for trainees covered 19 questions. Each set consisted of a mix of open and closed questions and took approximately seven minutes to complete.

The survey was advertised electronically on three major international science communication mailing lists - Psci-Com, ${ }^{18}$ BIG-Chat, ${ }^{19}$ and PCST, ${ }^{20}$ via group email, with a reminder sent out 11 days before the survey closed.

The online survey was completed by 87 respondents, distributed as follows: 39 trainers; 26 scientists; and 22 explainers. Not all respondents answered every question; for this reason the number of respondents (n) is indicated on each of the figures provided here. Although these numbers are not entirely representative, the wide range of programmes involved means that the information obtained provides a useful insight into common strengths of STEM training programmes. 


\section{Interviews}

Interviews were conducted in order to explore specific issues in more depth than possible with the online survey, and also to clarify findings yielded by preliminary analysis of the survey responses. Sixteen semistructured telephone interviews were conducted, divided as follows: 5 trainers; 5 scientists; 6 explainers. Interviewees represented 15 different training programmes, with only two explainers having attended the same course. The interviews were audio-recorded and subsequently transcribed.

\section{Data analysis}

The quantitative data was analysed in Microsoft Excel 2007 to identify trends in the opinions of respondents. The data sample obtained was insufficient for rigorous statistical analysis; however it was possible to identify broader trends.

The qualitative data (open-ended questions from survey and interview transcripts) was analysed using open coding and axial coding as identified by Strauss and Corbin. ${ }^{21}$ In open coding, concepts are identified in the data, and categories and sub-categories are established. In axial coding, the codes are related and linked to each other. The two types of coding are not necessarily sequential. ${ }^{21}$ The link between quantitative and qualitative data was made by, where possible, using common categories to those used in the survey in the development of the qualitative data code-frame.

\section{Results}

\section{Profile of respondents}

Participants represented a wide geographical spread, covering 17 different countries and 6 continents. The distribution was somewhat biased towards native English-speaking countries, with $57 \%$ of respondents coming from the UK, 16\% from Australia and 4\% each from Ireland and the USA.

The respondents were predominantly female $-60 \%$ for trainers, $55 \%$ for scientists and $82 \%$ for explainers. This follows data recently observed by Miller ${ }^{22}$ for the UK science communication community, which identified the contributors as $69 \%$ female.

The age distributions across the three groups were quite different. Within the trainers' group the age of the respondents was skewed towards the older age ranges; half of the trainers were in the 45-64 age group, with age groups $25-34$ and 35-44 accounting for 20\% of the respondents each. For scientists, $69 \%$ of respondents were between 25 and 44 years old. The explainers' group was the youngest group, with $50 \%$ of respondents being aged $25-34$ and $23 \%$ between the ages of 35 and 44 . The differences in the explainer / trainer age distributions are unsurprising given the experience one needs to gather before becoming a trainer. In the case of the scientists however, this data somewhat contradicts the findings of the Royal Society's 2005 study, ${ }^{5}$ which concluded that "Public engagement was more likely to be undertaken by... those older than 40 years". Different recruitment methodologies between the surveys almost certainly account for this discrepancy; further research on a wider scale would be beneficial to clarify the situation, especially at an international level.

\section{Profile of the training programmes covered}

In total, 47 different training courses were considered in this research. Figure 1 shows that half of the programmes covered in the quantitative part of this study focused on Public engagement with science (PES) and how to empower the trainees with the skills to better discuss issues and engage public audiences. The second most common type of programme covers Communication skills more broadly, with $35 \%$ of responses. Additionally, $3.5 \%$ of responses referred to media training, which was not an intended focus of the survey. 


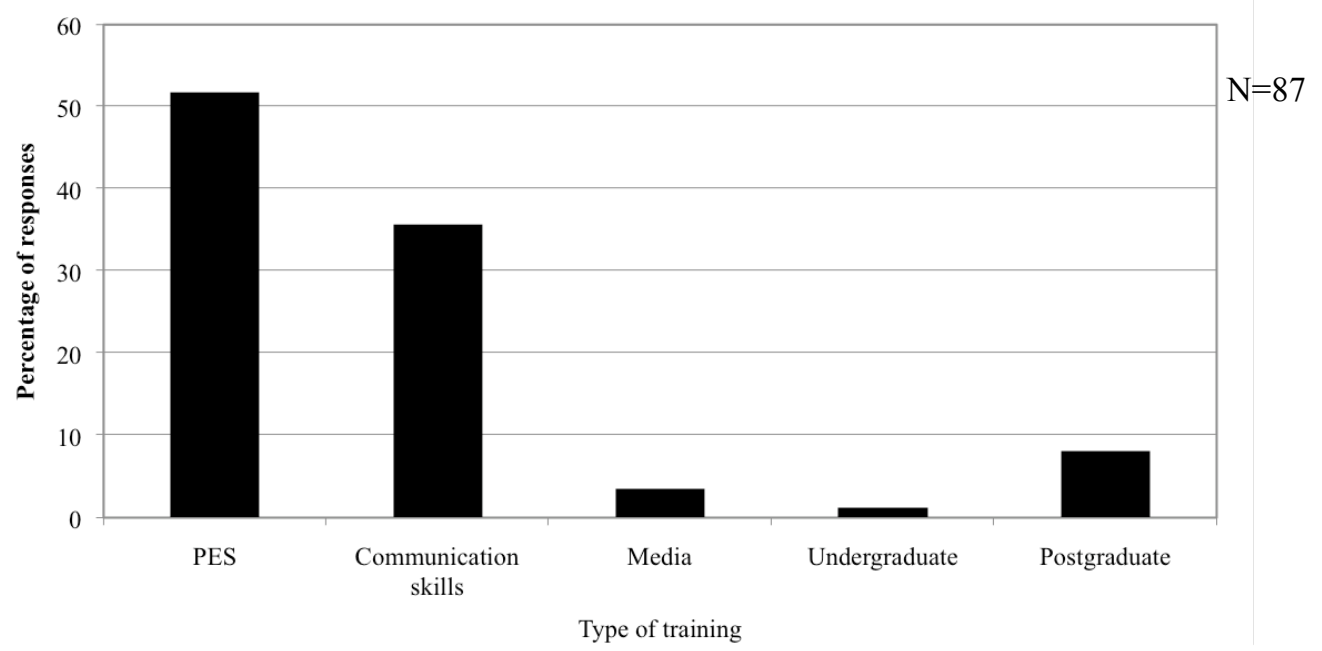

Figure 1. Training courses attended by the respondents to the online survey. The programmes have been categorised into types by the authors (rather than listing specific programme details) in order to maintain participants' anonymity and confidentiality. PES Course focus on public engagement with science; Communication skills: course focus on communication; Media: course with a media focus; Undergraduate: science communication class/module within a university degree; Postgraduate: dedicated postgraduate degree in science communication, for example MSc, Diploma etc.

All the interviews conducted for this study spanned across the categories of PES and Science communication described in figure 1. It is worth noting that within this study, respondents were not asked to specify the model of the training programme (e.g. in-house or external) however in hindsight this aspect may provide useful insights and would be valuable to include in future work.

\section{Rationale for attendance}

The majority of trainees attend training courses on public communication for personal development. This rationale has previously been identified by explainers and scientists in the evaluation of specific individual training programmes such as DOTIK ${ }^{9}$ and Meet the Scientist. ${ }^{23}$ Motivation is key to the success of training ${ }^{24}$ and the fact that trainees undergo training with a personal motivation is in itself a positive sign. Furthermore, over $90 \%$ of trainees said the courses met their expectations.

\section{Feedback on training - overview}

The training courses were rated highly and were valued by trainers and trainees alike, as seen in figure 2 . Importantly, the courses were seen as useful and interesting by all respondents, which is a positive finding of this research, strongly corroborated by the outcome of the interviews. Furthermore, both Delivery (all groups) and Trainer (an option available to the trainees only) also scored highly, indicating the trainers are coming across well to the trainees. One respondent to the survey commented: “...the trainers, they were really good and knew what they were doing." This is also a positive finding since empathy with the trainer aides the success of the training. ${ }^{25}$

Interestingly, there was some discrepancy between how trainers and trainees rated the Usefulness of the courses. Almost $80 \%$ of trainers self-rated their courses at the highest possible level of usefulness, whilst only $\sim 45 \%$ of trainees gave a top level rating of this aspect. This finding highlights the need for greater strategic direction within the industry regarding the provision of training programmes, with greater acknowledgement of the needs of the trainees. 


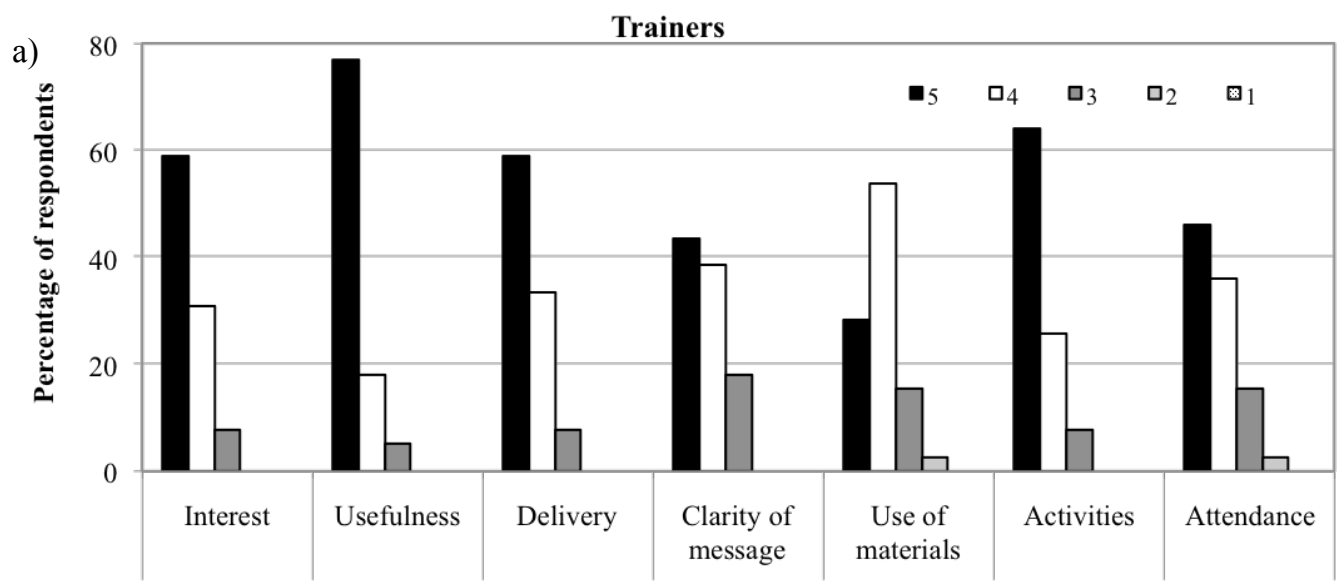

$\mathrm{N}=39$

Overall, how would you rate the training courses you deliver?

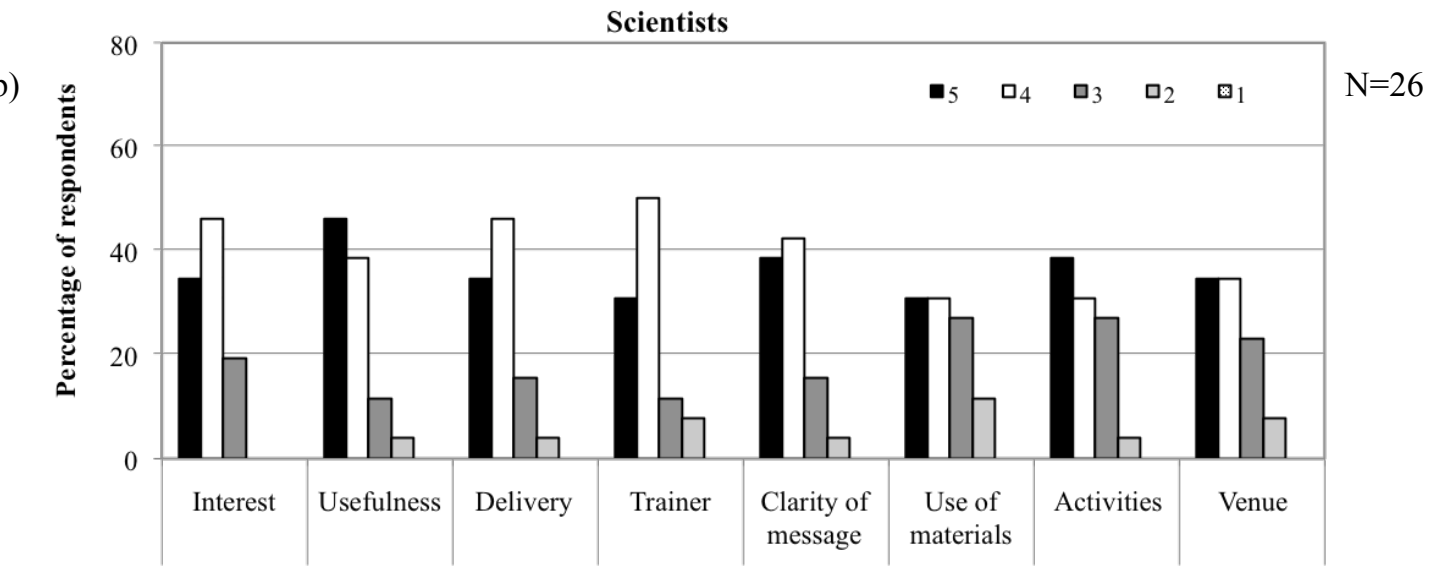

Overall, how would you rate the training courses you have attended?

c)

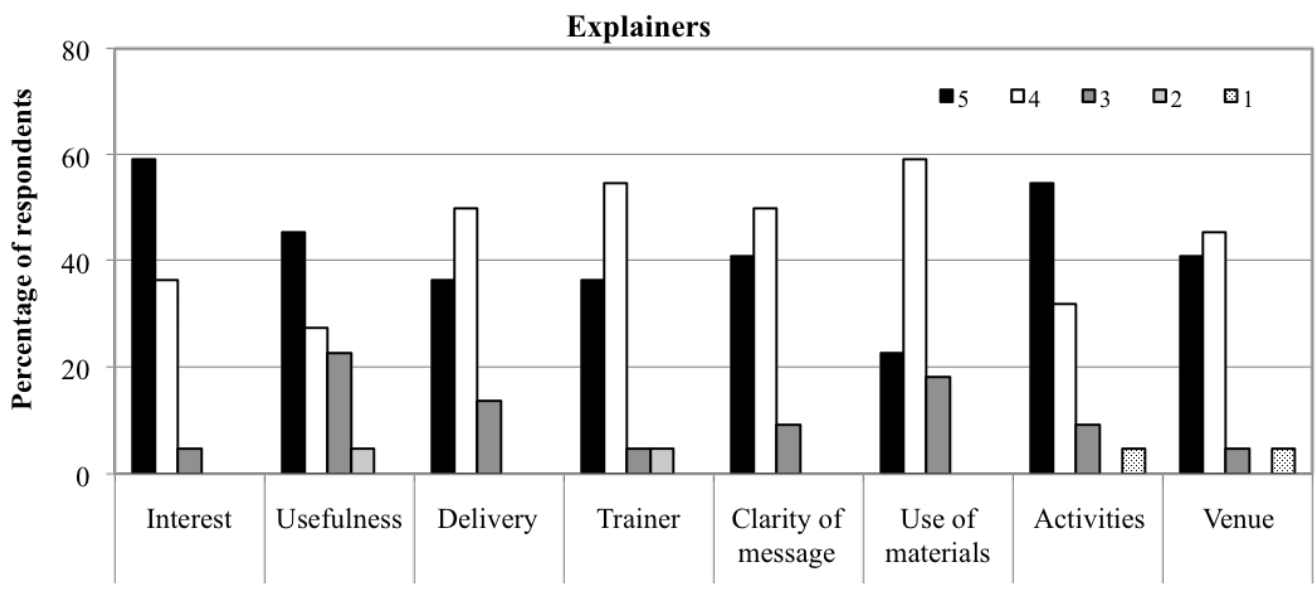

Overall, how would you rate the training courses you have attended?

Figure 2. Rating of different aspects of the training course (5=highest score). a) Trainers; b) Scientists; c) Explainers. 


\section{Effectiveness of specific activities}

Trainers and explainers have a common view on Activities, with $64 \%$ and $55 \%$ respectively allocating the top possible rating. In the case of scientists however, only $39 \%$ of respondents gave the top ranking to Activities. This perception was further investigated in a specific question within the survey regarding Activities, where respondents were asked to rank in priority order different types of activities according to their effectiveness. Table 1 shows the data from this question represented in two separate ways: firstly, by considering only the responses which were given the top priority order by the respondents, and secondly, by combining both the first and second priorities they identified.

\begin{tabular}{|c|c|c|c|c|}
\hline & & Trainers & Scientists & Explainers \\
\hline \multirow{4}{*}{$\begin{array}{l}\text { Considering first } \\
\text { priority only }\end{array}$} & Position 1 & Group work & Discussions & Discussions \\
\hline & Position 2 & Discussions & Role play & Role play \\
\hline & Position 3 & Presentations & Debates & Icebreakers \\
\hline & Position 4 & Other & Group work & $\begin{array}{l}\text { Group work/ } \\
\text { Presentations }\end{array}$ \\
\hline \multirow{4}{*}{$\begin{array}{l}\text { Considering } \\
\text { priorities } 1 \& 2 \\
\text { combined }\end{array}$} & Position 1 & Discussions & Discussions & Discussions \\
\hline & Position 2 & Group work & Role play & Group work \\
\hline & Position 3 & Presentations & Debates & Role play \\
\hline & Position 4 & Other & Group work & Presentations \\
\hline
\end{tabular}

Table 1. Priority ordering of activities according to their effectiveness.

As table 1 shows, Discussions were considered the most effective activity by both scientist and explainer trainees. Trainers also see Discussions as a highly effective activity, especially when trainers' first and second priorities are combined. Discussions were also highlighted by the survey respondents when asked to identify the "best" feature of the training: "Being able to openly discuss and debate different presentation styles". The reason for this unanimous view on the importance of Discussions might be related to the participants being more likely to listen to their peers about attitudes and their importance than they are to the trainer. ${ }^{24}$ This explanation was supported by the trainees within the interviews:

“...the three of us [trainees] as a team were constantly working together and giving feedback to each other and that was really useful"

"we do go and see each other's shows from time to time and give everyone a little bit of constructive criticism"

Despite this common ground on Discussions, other activities have different levels of appreciation between groups. In particular, Role play was highly valued by trainees but not trainers. Ultimately it is the trainers who determine the format of the training. Incongruence between the activities valued by trainers and those valued by their trainees might lead to exclusion of activities that are seen as very effective by trainees, at the expense of deeper impact of the programme.

Group work, although valued by all groups, was judged differently, with trainers and explainers considering it more effective than scientists. In addition, Presentations by students were seen as effective by trainers and explainers, but not by scientists. These two points suggest that there is more affinity between the views of trainers and explainers, in terms of the types of activities that are most effective, than between scientists and trainers or even scientists and explainers. This evidence highlights distinct training needs and views between scientists and explainers. 


\section{Use of materials}

When compared with the other responses in figure 2, Use of materials was less positively rated across all three respondent groups; in fact, $12 \%$ of scientists rated this aspect as "poor" (a value of 2 on the 5-point scale), as shown in figure $2 \mathrm{~b}$. The underperformance of the use of materials within existing training programmes is of concern, since materials are a support which greatly assists learning. ${ }^{24}$ This is also acknowledged by trainers, with a suggested improvement from the survey being: "More variety in use of materials".

The two most commonly used materials within a course were PowerPoint and Handouts (materials given to trainees). Considering today's technological society, the pervasive use of PowerPoint comes as no surprise. This tool was favourably rated by all groups, albeit more strongly by trainers $(84 \%$ positive responses) than trainees (just over $60 \%$ positive responses).

Handouts scored highly with trainers and explainers ( $85 \%$ and $77 \%$ of positive responses, respectively). Scientists, although rating it in line with their overall rating for other materials, do not value it as much as the other groups, with only $63 \%$ of positive responses. Clarification on these differences in ratings between scientists and explainers was sought during the interviews. What emerged from the research was that handouts are mainly used by trainers to emphasise aspects of the scientific content; this explains why handouts are more valued by explainers, who more often need to work outside their scientific comfort zone. One explainer commented during the interview:

"It's probably hard content wise. I came from a very scientific background, but I know there are some people at work who haven't come from a scientific background, which is really, really good... they've got completely different skills, but they do struggle with the science content. They do find it quite hard to get that kind of level of scientific knowledge... I think a lot of people do get a bit worried about the scientific content."

\section{Best practice}

Respondents were asked to outline aspects they considered the 'best' and 'worst' features of the training programmes they had experienced. To allow greater depth these questions were phrased as open questions, with the resulting answers categorised into themes. The key findings of this qualitative analysis, from both the survey and interview data, are summarised in table 2.

\begin{tabular}{ll}
\hline Category & Sub-category \\
\hline Style & Interactive/practical $(\mathrm{T}, \mathrm{S}, \mathrm{E})$ \\
\cline { 2 - 2 } Activities & Bespoke to group $(\mathrm{T})$ \\
\cline { 2 - 2 } Topics & Practice at live event $(\mathrm{T}, \mathrm{S}, \mathrm{E})$ \\
\hline \multirow{2}{*}{ The people } & Reflection/discussion of learning outcomes $(\mathrm{T}, \mathrm{S}, \mathrm{E})$ \\
\cline { 2 - 2 } & More than one trainer $(\mathrm{T})$ \\
\hline
\end{tabular}

Table 2. Summary of best practice aspects of existing training programmes. The responses are categorised according to which type of interviewee made the comment: $\mathrm{T}$ - Trainer; $\mathrm{S}$ - Scientist; E - Explainer.

An Interactive style was found to be essential to the success of training programmes. In addition, two other strong themes emerged: Demonstration followed by own performance and feedback; and Practice at live event. Both these aspects are very much "learning by doing", often suggested as very important 
within adult training scenarios; this approach fits in with andragogy - the way adults learn - which places the emphasis on what the learner is doing. ${ }^{24}$ This was strongly supported within the interviews by both trainers and trainees:

Trainee: "In my mind, the best way that you can be trained it is to actually go and do it yourself. And when you're doing that you have someone else to give you a bit of feedback"

Trainer: "...the most important thing, I think, is that they get up and have a go and we're able to give them feedback in a positive way"

It is relevant to point out that the "own performance" mentioned above can be seen, in lack of a real setting and/or live audience, very much like a Role play activity, which was also highly valued by trainees responding to the survey. The importance of feedback in this context should also be highlighted; constructive advice on the trainees' performance and progress is highly valued, as confirmed by a respondent to the survey: "have the trainers see us perform in front of a real audience and give us feedback'.

Many respondents believed that a real event with a live audience removes the artificiality often associated with a role play scenario, where the audience is "not real". Therefore, being able to practice within the proper event setting strengthens and consolidates the learning and confidence of trainees.

Trainees also felt that a debriefing session which allows for Reflection and discussion of learning outcomes was particularly effective. This process allows trainees to not only make sense of what has been covered in a structured way but also to take more responsibility for their own learning.

Trainers highlighted that having More than one trainer per session was very effective, since it brings complementary aspects to the training and makes the session more dynamic, adding strength to the course. In the words of one trainer:

“...having two or three people delivering, it's a real strength because we bring different skills."

Another trainer considers it essential to have more than one trainer per session because:

"it gives a bit of focus, [...] we have slightly different view points, $[\ldots]$ and complement each other well, while making the delivery more dynamic."

Reece and Walker ${ }^{24}$ emphasise team teaching, particularly for large groups, and note as advantages that the trainers can work to their personal strengths and that teamwork produces a better course. The trainers also pointed out the importance of trainees Interacting with real practitioners or peers involved in science communication. This aspect was mentioned by trainees however the emphasis placed upon it was less than by the trainers.

Trainers also mentioned that when possible, courses that are Bespoke to the group - tailored to the trainees' needs and abilities - are preferable. According to the trainers, this aspect links strongly to the trainees' motivation for attending training courses, but it also allows the trainers to make the most of the trainees' strengths, as one trainer put it during an interview:

"We knew what they needed and we knew who they were and then on the day we... [took] activities that we had prepared and we... adjusted them to what they wanted to do and... readjusted them as we went along, according to what the participant did or didn't feel comfortable doing."

On a final note, it is important to mention that although suggested improvements focused very much on strengthening the aspects covered above, one improvement stood alone - the Increase in the scientific content of training courses for explainers. Although the explainer group felt their training was highly effective, additional support on scientific content would be beneficial to their role and performances. One interviewee explained:

"...it would have been helpful to have more structure to that [scientific information] because as it were [sic] I did that completely myself, under my own guidance... if there was some structure to... complement the actual training in terms of delivery and the practical side of things that might have been helpful." 
The request for this improvement also links to explainers' high ratings of Handouts, which they commonly perceived to be associated with additional scientific information. Since explainers come from a range of different backgrounds and are expected to be comfortable with all sorts of science contexts, ${ }^{12}$ it is understandable that an increase in scientific content is seen as a much appreciated support.

\section{The impacts of training}

This study identified positive changes in trainees that benefit public engagement as a whole. There was an increase in involvement in science communication events by both scientists and explainers after the training. In addition, figure 3 outlines how the trainees consider the course has affected various relevant skills.

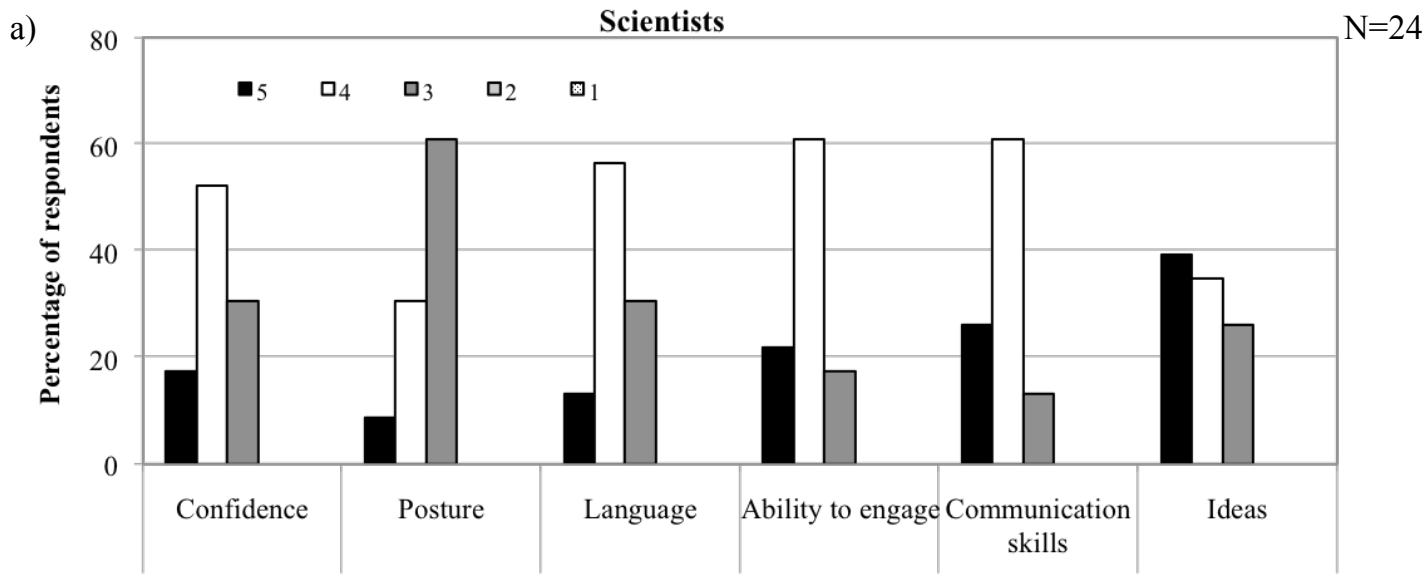

Aspects relating to performance that have changed as a result of the course

b)

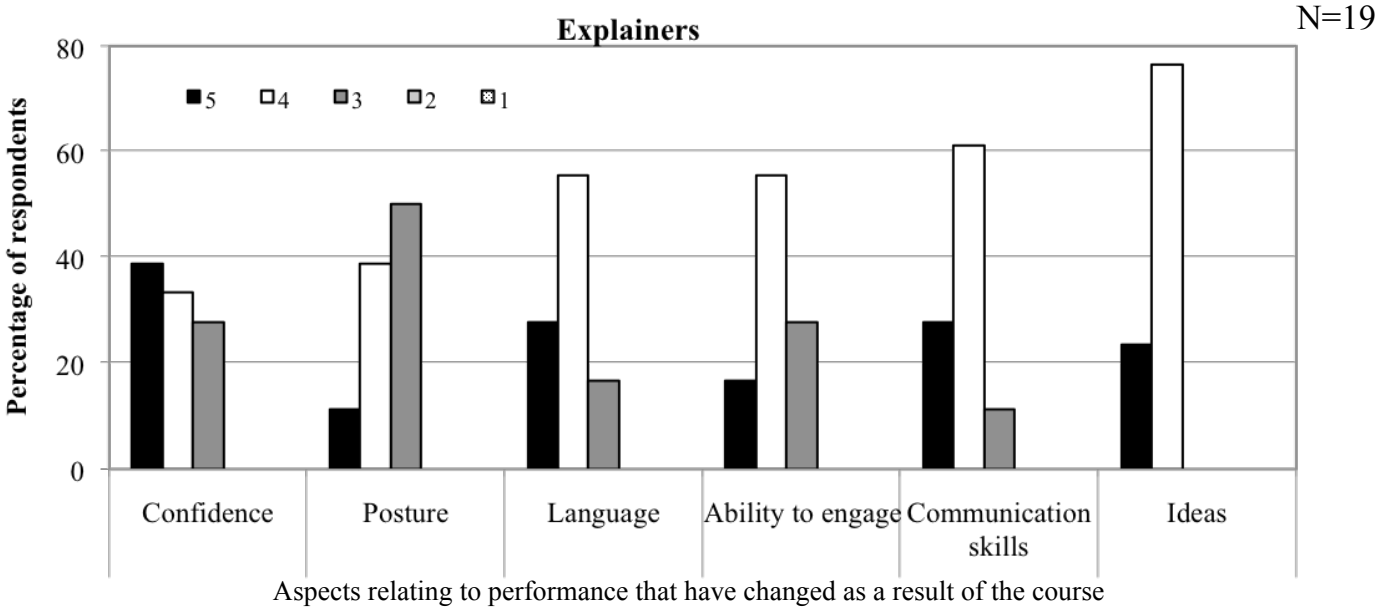

Figure 3. Trainees' perceived changes in different aspects relating to performance in public communication events as a result of the public communication training course $(5=$ much better; $3=$ stayed the same; $1=$ much worse). a) Scientists; b) Explainers. 
Trainees feel they have better communication skills, are more able to engage with the public, and are more confident in their role. As best described by one trainee during the interviews: "My confidence has definitely increased after the course". Whilst the majority of both scientists and explainers felt that their posture was unaffected, both groups felt their language and ideas had improved, with a unanimous vote by the explainers surveyed acknowledging a positive effect on their ideas.

\section{Guidelines for best practice in STEM communications training}

The results from this research suggest that according to best practice, training courses for STEM (Science, Technology, Engineering \& Mathematics) communications skills should:

- be practical and interactive;

- include a demonstration activity for the trainees to observe and reflect upon, followed by a demonstration by the trainees themselves, complemented by constructive feedback; if possible, this aspect should be delivered during a real science communication event to ensure contact with real audiences.

In addition, wherever possible, training courses should:

- include a session on reflection/discussion of learning outcomes to encourage the trainee to be responsible for his/her own learning;

- improve the quality of materials and use them more effectively;

- enable contact between trainees and peers involved in science communication, to promote the sharing of experiences;

- be delivered by more than one trainer; this provides support to the trainer while making the session more complete and dynamic;

- be bespoke (i.e. tailored to suit the trainees); when this is not possible, the trainer(s) should seek a sound knowledge of the trainees' needs, abilities and expectations and adjust the training course accordingly.

Note 1: Scientists and explainers are different science communicators in their roles, abilities and needs and should therefore attend training courses designed specifically for each group.

Note 2: When designing training courses for explainers or scientists working out of their scientific area of expertise, special attention should be given to the scientific content including provision of additional support materials.

\section{Conclusions}

Overall, the training courses are extremely valued by trainers and trainees alike. They are seen as useful and responsive to trainees' needs. A positive clear outcome of training is the increase in participation in science communication events. Trainees also feel more confident and better equipped to engage with the public.

An Interactive style was found to be a key element of a training course. There was also an agreement among participants on the importance of Discussions in learning. In addition, demonstrations of good practice followed by own performance and feedback were highly valued; within this scenario, it is possible to fit Role play, another popular activity for trainees. Participants would like the training courses to provide the opportunity for trainees to be involved in a live event, or come into direct contact with a real audience. They also feel that a reflective session on learning outcomes is of key importance.

There were differences between groups in terms of their appreciation of different aspects of the programmes; interestingly, the perception of the usefulness of the courses differs between trainers and trainees, with the former judging the programmes to be more useful. This finding draws attention to the need for a consistent strategic direction within the industry regarding the provision of training programmes, focusing more on the needs of trainees.

The appreciation of Activities also differed between groups, with trainees valuing Role play more so than trainers, which could potentially be leading to the exclusion of this activity from training, with consequent reduction in effectiveness. Differences found between scientists and the other groups also support the need to deliver separate training programmes according to the type of trainees.

This research will empower both the providers of science communication training programmes as well as recipients, through clarifying aspects of best practice and providing evidence for the effectiveness of 
STEM training programmes. However there is still a great deal of further work to be done. Given the international breadth of science communication, particularly within museums and science centres, of particular interest would be a comparison of cultural influences on training programme formats, especially in non-native English speaking countries.

\section{Further studies}

The development of a widely accepted and publicly available evaluation mechanism, where training courses are evaluated based on common criteria and are thereby more directly comparable, is very desirable but realistically very hard to achieve. Quite apart from the difficulties involved in agreeing suitable criteria, most trainers already have existing evaluation mechanisms in place for their own internal use, and are unlikely to see significant enough advantages in joining a common system to warrant the effort involved to do so.

In the absence of a common evaluative framework, there are many other highly relevant and interesting potential research opportunities in this area. In particular, comparative evaluative studies which take a complementary approach to the present research would be very valuable, for example incorporating a direct comparison of programme content across different courses, including observations performed by an external researcher. Future studies could also take a more in-depth approach in order to distinguish the impacts of features such as duration, location (particularly whether internal or external) and whether the delivery team has an existing relationship with the delegates.

As noted within the 'Profile of respondents' section, a discrepancy was observed regarding the age distribution of participants within this survey and previous work. ${ }^{5}$ This may be a reflection of the international nature of this research (compared to the single country - UK - focus of the previous Royal Society survey) and/or the different participant recruitment methods used between the two surveys. Further investigation of the age distribution of scientists participating in STEM communications activities in specific countries would be very useful here in order to identify the reason(s) for the inconsistency.

Finally, cultural implications may also have an effect on the results; the majority of participants within this work were native English speakers however further analysis on a country-by-country basis would provide excellent insight into the practices that best suit local conditions.

\section{Notes and references}

${ }^{1}$ J. Potocnik (2005), Welcome by Science and Research Commissioner Potocnik, in: European Commission, CER 2005 Programme 3. Retrieved Aug 25, 2008; available at: http://ec.europa.eu/research/conferences/2005/cer2005/pdf/cer2005 final progr_051104.pdf.

${ }^{2}$ P. Maeseele (2007), Science and technology in a mediatized and democratized society, Jcom 06(01): A2, retrieved Aug 25, 2008; available at http://jcom.sissa.it/archive/06/01/Jcom0601(2007)A02/.

3 The Royal Society (2006), Science \& The Public Interest - Communicating the results of new scientific research to the public, published by The Royal Society, London. Retrieved Aug 25, 2008; available at: http://royalsociety.org/downloaddoc.asp?id=2879.

${ }^{4}$ OST/The Wellcome Trust (2000), Science and the Public: A Review of Science Communication and Public Attitudes to Science in Britain, published by The Wellcome Trust, London. Retrieved Aug 25, 2008; available at:

http://www.wellcome.ac.uk/stellent/groups/corporatesite/@msh peda/documents/web document/wtd003419.pdf.

${ }^{5}$ The Royal Society (2006), Survey of factors affecting science communication by scientists and engineers, published by The Royal Society, London. Retrieved Aug 25 2008; available at http://royalsociety.org/page.asp?id=3180.

6 The Royal Society (2009), Communication skills training - course programme. Retrieved Feb 15, 2009; available at: http://www.royalsoc.ac.uk/page.asp?id=2409.

7 The Science Communication Unit (2009), Science Communication Masterclass. Retrieved Feb 15, 2009; available at: http://www.scu.uwe.ac.uk/index.php?q=node/81.

${ }^{8}$ Intute, Science Communication Courses. Retrieved 20 February, 2009; available at: $\mathrm{http}: / / w w w . i n t u t e . a c . u k / h e a l t h a n d l i f e s c i e n c e s / c g i-b i n / b r o w s e ~ p s c i c o m . p l ? i d=45$.

9 DOTIK - European Training for Young Scientists and Museum Explainers - A report (2007), published by the DOTIK partnership online. Retrieved Aug 25, 2008; available at: http://www.dotik.eu/materiali/DOTIK\%20-\%20report.pdf.

10 OST/MORI (2005), Science in Society - Findings from Qualitative and Quantitative Research, published by The Office of Science and Technology, Department of Trade and Industry, London. Retrieved Aug 25, 2008; available at: http://www.ipsospublic-affairs.com/polls/2004/pdf/ost.pdf.

11 The ENSCOT Team (2003), Enscot: The European Network of Science Communication Teachers, Public Understanding of Science 12(2): 167. Retrieved Aug 25, 2008; available at http://pus.sagepub.com/cgi/reprint/12/2/167. 
${ }^{12}$ P. Rodari and M. Xanthoudaki (2005), Beautiful Guides. The Value of explainers in science communication, Jcom, 04(04): C01. Retrieved Aug 25, 2008; available at http://jcom.sissa.it/archive/04/04/C040401/.

${ }^{13}$ Research Councils UK / Department for Innovation (2008), Universities and Skills, Public Attitudes to Science 2008 - A Guide, published by Research Councils UK, Swindon. Retrieved Aug 25, 2008; available from:

http://www.rcuk.ac.uk/cmsweb/downloads/rcuk/scisoc/pas08guide.pdf.

${ }^{14}$ Eurobarometer, Europeans, Science and Technology, Special Eurobarometer 224 / Wave 63.1, 2005. Retrieved Aug 30, 2008; available at http://ec.europa.eu/public_opinion/archives/ebs/ebs_224_report_en.pdf.

15 M.W. Bauer, N. Allum and S. Miller (2007), What can we learn from 25 years of PUS survey research? Liberating and expanding the agenda, Public Understanding of Science 16(1): 79. Retrieved Aug 25, 2008; available at:

http://pus.sagepub.com/cgi/content/abstract/16/1/79.

${ }^{16}$ C. Johnson (2005), Training science centre Explainers. The Techniquest experience, Jcom 04(04): C04. Retrieved 30 Aug, 2008; available at: http://jcom.sissa.it/archive/04/04/C040404/.

${ }^{17} \mathrm{http}: / /$ surveymonkey.com.

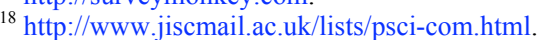

${ }^{19} \mathrm{http}: / /$ www.big.uk.com/.

${ }^{20} \mathrm{http}: / /$ mailmanlist.net/cgi-bin/mailman/listinfo/pcst.

${ }^{21}$ A. Strauss and J. Corbin (1998), Basics of Qualitative Research: Techniques and Procedures for Developing Grounded Theory, $2^{\text {nd }}$ Edition, SAGE Publications, London.

${ }^{22} \mathrm{~S}$. Miller, So Where's the Theory? on the Relationship between Science Communication Practice and Research, in C. Donghong, M. Claessens, T. Gascoigne, J. Metcalf, B. Schiele and B. Shunke (eds.) (2008), Communicating science in social contexts - New models, new practices, Springer, Netherlands.

${ }^{23}$ L. Webb and R. Mist (2007), Meet the Scientist - Final Project Report, Ecsite-UK.

${ }^{24}$ I. Reece and S. Walker (1997), Teaching, Training and Learning - A Practical Guide, $3^{\text {rd }}$ Edition, Business Education Publishers Limited, Great Britain.

${ }^{25}$ J. Daines, C. Daines and B. Graham (1993), Adult Learning, Adult Teaching, Department of Adult Education, University of Nottingham, Nottingham.

\section{Authors}

Joana Silva is the Sun Dome Development Officer at UKAEA. She has been involved with educational outreach at various levels, including the Cheltenham Science Festival and Bristol Festival of Nature, before joining UKAEA. This research was conducted as part of Joana's MSc in Science Communication at the University of the West of England, Bristol. E-mail: Joana.Silva@ukaea.org.uk.

Dr Karen Bultitude is a Senior Lecturer in Science Communication at the University of the West of England, Bristol. She specialises in innovative and practical methods of taking science directly to public audiences, both within the UK and internationally. She has devised, delivered and/or evaluated multiple training programmes for both researchers and explainers and is one of nine Public Engagement Mentors for the UK's Engineering and Physical Sciences Research Council (EPSRC).

E-mail: karen.bultitude@uwe.ac.uk.

How to CITE: J. Silva and K. Bultitude, Best practice in communications training for public engagement with science, technology, engineering and mathematics, Jcom 08(02) (2009) A03. 